\title{
PART-MACHINE GROUP FORMATION WITH OPERATION SEQUENCE, TIME AND PRODUCTION VOLUME
}

\author{
Kumar, L. ${ }^{*} \&$ Jain, P. K. ${ }^{* *}$ \\ "Department of Mechanical Engineering, J.M.I., New Delhi-110025, India \\ ** Department of Mechanical and Industrial Engineering, I.I.T., Roorkee, India \\ E-Mail: lokeshkrsax@rediffmail.com; pkjain123@gmail.com
}

\begin{abstract}
This work presents an algorithm for design of cellular manufacturing system. It includes important production data such as Operation sequence, operation time, production volume \& Intercellular travel loss. Adapted design activity organizing model \& image representation model in computer vision is used to incorporate production data into model. Machine sequence Part Load Volume Matrix is formed. Orthographic view part grouping analysis is used for part family formation. Machines are allocated on basis of their utilization for a part family. A new performance measure is proposed considering effect of occupied elements, void, and exceptional elements. The performance of algorithm is examined and compared with existing methods in its class. The result show performance of proposed algorithm is comparable \& of good quality with existing methods. Proposed algorithm has immense industrial application. It can be implemented by using free software, Scilab. It can also be implemented by use of commercial softwares.

(Received in March 2008, accepted in August 2008. This paper was with the authors 1 month for 1 revision.)
\end{abstract}

Key Words: Cellular Manufacturing, Part Families and Machine Cells, Algorithm

\section{INTRODUCTION \& LITERATURE REVIEW}

Businesses are restructuring and re-engineering themselves in response to the challenges and demands of $21^{\text {st }}$ century. The $21^{\text {st }}$ century business will have to overcome the challenges of customers seeking high-quality, low cost products, and be responsive to customer's specific unique and rapidly changing needs. Therefore, the design of manufacturing systems is becoming more important and a continuous task.

The cellular manufacturing is an important manufacturing system. In recent years, there have been continuous research efforts to study different facet of CMS. Most of them concentrated on distinguishing the part families and machine cells with the objective of minimizing intercellular and intracellular part movements. This is known as machine-part grouping problem (MPGP) which is a crucial process while designing CMS.

Most of the methods of cell formation are based on machine component incidence matrix (that is 0 \& 1) alone. [1-11]. A number of researchers proposed similarities coefficients based approaches to solve the $\mathrm{CF}$ problem in the literature.

An approach is proposed that is based upon the calculation of an average voids value $(A V V)$, which indicates the average number of newly produced voids when a pair of machine groups is combined [12]. Studies indicated that similarity coefficients based method (SCM) is more flexible than other CF methods [13].

Some components may not be finished within only one cell; they have to travel to another cell(s) for further operation(s). Under this circumstance, intercellular part movement will occur. Different order/sequence of machine cells allocation may result in different total intercellular movement distance unit. It should be noted that if the production volume of each 
part is very large, then the total number of intercellular movement will be further larger. The sequence of machine cells \& Production volume is important in this aspect [14].

Venugopal \& Narendran made use of genetic algorithm for clustering. A clustering approach [15] of the non-hierarchical type is proposed on the basis of sequence data [16]. Nair, J. G. \& Narendran, T. T. developed a method (ACCORD), clustering machines \& parts using sequence, ratio level data. However, they considered unity production volume for all parts.

Principal components analysis is used for evaluating the feasibility of cellular manufacturing without initial-part matrix clustering [3]. An approach is proposed for machine cells formation by applying factor analysis to the matrix of similarity coefficients [2]. The proposed approach has not considered other important production factors such as operation sequence, volumes \& processing times. An approach is proposed for machine cells formation by applying a multivariate analysis model to find the Eigen values and eigenvectors on the double centering matrix [8]. This work has also not considered other production data such as sequence, volumes $\&$ processing times.

Most of the existing methods require an a priori specification of the upper bound on the number of machines within a cell and/or the number of cells. This contradicts the fundamental philosophy of GT that groups exist naturally and that the task of the analyst is to identify them if they exist [9].

There is limited industrial application due to unavailability of software program supporting solution of CF problems or these are expensive softwares [17]. Most of the time it is required to have knowledge of programming, difficult \& complex optimization techniques such as genetic algorithms, neural networks etc. In this work, an attempt is made to develop an algorithm, APOSTVUIT. It is the name for an Algorithm with Part Operation Sequence, Operation Time, Production Volume, Machine Utilization Gain \& Inter Cell Travel Loss for formation of part families \& machine cells.

\section{APOSTVUIT - METHODOLOGY}

In production management, group technology is a system of layout which combines the benefits of process layout and product layout. The objective of group technology layout is to subdivide the total number of components and machines into subgroups of machinecomponent cells such that the required machines of all components which are assigned to each cell are maximally available within that cell it.

\subsection{Mathematical Modeling of machine-part}

In this problem, parts are assumed as objects and machines which process the part, are treated as attributes of that part. The processing requirement of parts can be represented in form of object-attribute (i.e. part-machine) incidence matrix. The rows of this matrix represent machines. Column of matrix represent the parts. Let us treat this matrix as Machine Sequence Part Matrix, MSPM .Step-by-step procedure for MSPM formation is given as follows:

Step 1 Design activity organizing Model and Part Machine Sequence Representation

According to Kusiak and Wang [18], design process is described as a sequence of interrelated activities that begins with an initial set of customer requirements and with complete description of a product that satisfies these requirements. To simplify and increase the efficiency of the design process, one needs to analyze the information flow between design activities and organize them, accordingly. 
An activity-activity incidence matrix and the corresponding directed graph (digraph) are used to represent design activities and relationship among them. A non-empty element in an incidence matrix represents a relationship between the corresponding (row and column) activities.

In part-family grouping problem, each part moves machine to machine in sequence. It is similar to design activity to activity in sequence. To model machine sequence, we make part machine to machine sequence matrix for each part. If the part visits the machine, corresponding element is assigned as unity. Number of one in this matrix represents sequence number of machine.

Now, for each part, make Part Machine to Machine Sequence Matrix (PMMSM), Part Machine to Machine Sequence Time Matrix (PMMSTM) \& Part Machine to Machine Sequence Time Volume Matrix (PMMSTVM). This is $m \times m$ matrix whose rows and columns represent sequence number of that machine for processing of part considered. Elements of this matrix have value 1 or 0 in PMMSM. Sequence number of a machine is given by total number of 1 in the row of that machine for part considered. Step-by-step procedure for PMMSM formation is as follows:

1. Allocate zero to all elements of row of machine if part does not visit that part.

2. If parts visit a machine first in sequence, allocate 1 to element of rows of that machines and column of all machines required by part.

3. If parts visit a machine second in sequence, allocate 1 to element of rows of that and column of machine required by part, (excluding the machine that is visited first in sequence.

4. If a part visit a machine third in sequence, allocate 1 to elements of rows of that and columns of machines required by part excluding the machine that is visited first and second in sequence.

5. Above procedure is followed for other machine sequence.

For PMMSTM multiply operation time of part-machine combination with respective machine row of PMMSM. Finally, multiply production volume (PV) of that part with elements of PMMSTM to get PMMSTVM.

Step 2 Image representation in computer vision analogy for part machine sequence representation

In computer vision [19], images are usually represented in matrix form. A square, $m \times m$ image (i.e. $m \times m$ pixels or image points in a two dimensional image) can be expressed as an $m_{2}$-dimensional image vector as

$$
I_{\text {mvec }}=\left(I_{m 1} ; I_{m 2} ; I_{m 3 ;} ; \cdots \cdots \cdots \cdots \cdots \ldots \ldots . . . \cdots I_{m^{2}}\right)
$$

where the rows of pixels in the image are placed one after the other to form a one dimensional image. For example, the first $m$ elements $\left(I_{m 1}\right.$..to.. $\left.I_{m_{m}}\right)$ will be the first row of the image; the next $m$ elements are the next row, and so on. The values in the vector are the intensity values of image, possibly a single grey scale value.

Let one have $p$ number of images. Each image is $m$ pixels high by $m$ pixels wide. One can create an image vector as described before. Now, one can put all the images together in one big image vector (i.e. image-matrix) like this:

$$
\text { Image Matrix }=\left[\begin{array}{c}
\text { ImageVect1 } \\
\text { ImageVect2 } \\
\\
\cdot \\
\text { ImageVectp }
\end{array}\right]
$$


For part-machine sequence model, we represent Part Machine to Machine Sequence Time Volume matrix, PMMSTVM of a part as an image. Numbers of images are equal to numbers of parts.

Now, make a matrix Machine Sequence Part Load Volume Matrix, MSPLVM with column $(p)$ representing parts and rows $\left(m_{p}=m \times m\right)$. For each part, rows of PMMSTVM are arranged into column one by one to make one dimensional column vector (i.e. image vector of that part). All image vectors (i.e. parts) are placed column wise to form big image vector (i.e. image-matrix).

\subsection{Modeling for machine-part analysis and grouping in cellular manufacturing:}

Here, aim is to group original input variables (machine / parts) into few factors (i.e. cells) which underlie the input variables. In other words, cell formation needs dimension reduction on the basis of some similarity measure or coefficients.

Step 1 Standardized Machine Sequence Part Load Volume (SMSPLV) matrix formation

Now, SMSPLV matrix is formed from MSPLV matrix. Here, elements of MSPLV are standardized by using formula [20].

$$
Z(I, J)=\operatorname{SMSPLV}(I, J)=[\{\operatorname{MSPLV}(I, J)-\operatorname{MSPLV}(J)\} / S D(J)]
$$

where, $\operatorname{MSPLV}(J)$ is the mean of elements of $J^{\text {th }}$ column of matrix MSPLV.

$S D(J)$ is standard deviation of elements of $J^{\text {th }}$ column of matrix MSPLV.

Step 2 Part-Part Correlation Matrix (PPCM) formation

Now, PPCM matrix is formed from SMSPLV matrix on the basis of similarity coefficient [21]. It is given as:

Element of PPCM:

$$
\begin{aligned}
& \operatorname{PPCM}(I, J)=1, \text { if } I=J, \\
& \text { otherwise, } \\
& \operatorname{PPCM}(I, J)=\frac{1}{m_{p}} \sum_{k=1}^{m_{p}}[\operatorname{SMSPLV}(K, I) * \operatorname{SMSPLV}(K, J)]
\end{aligned}
$$

Here, $m_{p}=m \times m$. This matrix represents measure of similarity between parts.

Step 3 Dimension reduction

Principle component analysis transforms a given set of interrelated variables into a new set of original variables, called the principal components \& is orthogonal to each other. So, the correlation between them is zero. The principal components are generated in a sequentially ordered manner with decreasing contributions to the variance. This property means that the data points can be rigorously separated into distinct clusters when projected into a space spanned by the first few principal components. This achieves the dimensionality reduction objective. Detailed description of this approach can be found in the relevant literature $[20,22]$.

Assuming the parts as the original set of variables, and the correlation matrix, PPCM, explaining the correlations between each pair of parts, we proceed to use the PCA framework for grouping the parts into separate independent clusters.

In the PCA method, the cells are extracted out by the eigen value - eigenvector analysis of the correlation matrix as presented in Eq. 2.

It finds a small number of principle components, recovering as much variability in data as possible. It means finding eigen vector and eigen values for equation, 


$$
\operatorname{det}\left(P P C M-\lambda(J) \cdot I_{m}\right)=0 ; J \in(1, p)
$$

where $I_{m}$ is identity matrix.

$$
\lambda(J) \in\left(\lambda_{1} \geq \lambda_{2}, \ldots \ldots \ldots, \lambda_{p}\right) \text { are eigen values (real and non-negative), }\left\{F_{1}, F_{2}, \ldots \ldots \ldots \ldots ., F_{p}\right\}
$$

are corresponding eigen vectors of matrix PPCM.

\section{Step 4 Orthographic View Part Grouping Analysis (OVPGA)}

Cluster analysis is a technique which groups persons / objects / occasions into unknown number of groups having similarities. Each rows of PCA matrix represent a point in multidimensional space (number of axis / dimension is equal to number of principle components). The line joining this point and origin of coordinate system is a vector (also that part). Orthographic projection of this vector in space on a plane of projection made of first and second principle components represents that part. This projected view is used for grouping purpose.

Represent $\mathrm{X}$-axis as first principle component and $\mathrm{Y}$-axis as second principle component (i.e. eigen vectors), now plot each variable (i.e. parts) with coordinates as (principle component 1 , principle component 2). Join this point with zero of coordinate system with a line. This line represents that part. Thus, draw Orthographic View. Angular distance between lines on Orthographic View is taken as measure of similarity. Parts with low angular distance become part of a family. Plot will show groups of part with almost same angular distance from first principle component.

- Two parts having low angular distance, assign to same cell.

- Two parts having almost $180^{\circ}$ angular distance, assign to different cells.

- If part does not belong to any of three categories, it is exceptional part.

(a) Compute angular distance of exceptional parts $\left(k_{p}\right)$ with first principle component axis, $\theta_{k i}$.

(b) Compute angular distance of exceptional part with other non-exceptional part (i), $\theta_{i k e}=\left|\theta_{i}-\theta_{k e}\right|$, where $\theta_{i}$ is angular distance of $i^{\text {th }}$ part with first principle component.

Find minimum $\theta_{i k e}$ and $k_{e}$ part is a member of part group for which, $\theta_{i k e}$ is minimum

\subsection{Assignment of machine to part families (i.e. Machine grouping)}

Now machines are allocated to the part families. The machine allocation should meet basic aim of maximum utilization of machines (i.e. resources) \& minimum loss due to intercell travels.

Step 1 Computes Machine Utilization Net Gain (MUNG) opportunity

For each machine, compute Machine Utilization Net Gain (MUNG) opportunity in different part families (i.e. cells). $M U N G$ of a machine $I$ for part family $K$ is defined as difference of Machine Utilization Opportunity Gain $(M U O G)$ of machine $I$ for part family $K$ and InterCell Travel Loss (ICTL) for machine $I$ for part families other than $K^{\text {th }}$ part family. Machine utilization opportunity gain of machine $I$ for part family $K$ is defined as sum of total processing time of all parts in part family $K$. Total processing time of $J^{\text {th }}$ part is multiplication of processing time of part $J$ on machine $I$ and production volume of $J^{\text {th }}$ part. Processing time of part $I$ is sum of operation time, setup time and other idle times. Intercell travel loss for machine $I$ and part family $K$ is sum of intercell travel losses for machine $I$ due to movement of parts belonging to part families other than part family $K$.

$M U N G$ in a part family $K$ is given as: 


$$
M U N G=M U O G-I C T L
$$

$M U O G$ in a part family $K$ is given as:

$$
\operatorname{MUOG}(K)=\sum_{\times}[(\text {Part load } / \text { unload time }+ \text { tool change time }+ \text { operation time }) \times
$$

Intercell Travel loss with other part families is given as:

$$
\begin{aligned}
I C T L & =\sum_{K 1=1}^{n_{\text {opt }}} \text { Intercell Travel Loss for a machine } I \text { for part families }(K 1 \neq K) \\
& \text { other than part family } K \text { (when machine is assigned to part family } K \text { ) }
\end{aligned}
$$

$I C T L$ for a part is given as:

$\begin{aligned} I C T L \text { for a part }= & (\text { load } / \text { unload time }+ \text { travel time in material handling device }) \times \\ & \times \text { Production Volume }\end{aligned}$

Step 2 Machines are allocated on the basis of MUNG, MUOG, and ICTL as:

(a) Allocate the $m^{\text {th }}$ machine to a part family for which $M U N G$ is largest.

(b) If tie occurs among cells, allocate the machine on the basis of MUOG.

(c) If tie occurs among cells, allocate on the basis of total operation cost opportunity for machine in a part family.

(d) If tie occurs; allocate on the basis of minimum intercell travel loss, ICTL.

If tie occurs, allocate on the basis of idle time cost

\subsection{Measure of Performance}

In CF problem, objective is to group machines and parts so as to minimize the number of intercell moves and to maximize the machine utilization within cells. In other words, there should be minimum number of non-zero elements (i.e. exceptional elements) outside the diagonal blocks. There are several measures like grouping efficiency (eq. 8) \& group technology efficiency (GTE) (eq. 11) etc., for representation of grouping performance. The measure (i.e. $G E$ ) treats all operation equally. However, when ordinal and ratio level data is considered, this measure does not represent true grouping performance.

$$
G E=\alpha\left[\frac{U E-E E}{\sum_{k=1}^{n o p f} m_{k} p_{k}}\right]+(1-\alpha)\left[1-\frac{E E}{m . k .-\sum_{k=1}^{n o p f} m_{k} p_{k}}\right]
$$

Harhalakis et al. [6] proposed group technology efficiency (GTE), considering ordinal level data (i.e. sequence of operation). It can be used to asses grouping performance.

Grouping technology efficiency is defined as ratio of the difference between the maximum number of intercell travel possible and the numbers of intercell travels actually required by system to the maximum numbers of inter-cell travels possible.

Maximum numbers of intercell travel possible in system,

$$
I_{p}=\sum_{k=1}^{n o p f} \sum_{J=1}^{n o p t k k)}[n(J, K)-1]
$$

where:

$$
\begin{array}{ll}
\text { nopf } & - \text { total number of part family or cell } \\
n o p f k(k) & - \text { total number of parts in } K^{\text {th }} \text { cell }
\end{array}
$$


$J \quad-$ part number in a cell

$n(J, K) \quad-$ maximum number of operation required by $J^{\text {th }}$ part in $K^{\text {th }}$ cell

Number of intercell travels actually required by system,

$$
I_{r}=\sum_{J=1}^{p} \sum_{W(J)=1}^{(n(J)-1)} t_{n(J) W(J)}
$$

where:

$$
\begin{aligned}
& p \quad-\text { total number of parts in system (i.e. CF problem) } \\
& J \quad-J^{\text {th }} \text { part in system (i.e. CF problem) } \\
& n(Z) \quad-\text { maximum number of operation required for } J^{\text {th }} \text { part } \\
& t_{n(j) w(J)}=0, \text { if operation } W(J) \& W(J)+1 \text { are performed in same cell. } \\
& =1, \text { otherwise. }
\end{aligned}
$$

$$
\mathrm{GTE}=\left(I_{p}-I_{r}\right) / I_{p}
$$

The development of a consistent classification and the corresponding designation of measures is a necessary approach. An efficiency measure must be developed for the overall measure of the cellular manufacturing systems so as to develop the method for subjective selection of parameters to decide the case-specific attributes. The non-diagonal measures such as clustering measure, bond-energy measure and the permuted measure should take into account the block-diagonal elements related measures such as the group efficiency, group efficacy, grouping index, quality index and group capability index.

Some other measures like global efficiency, group technology efficiency, and proportionate measures did not consider some important parameters such as unit distance cost and intercellular movement cost. Hence, the criteria for the various efficiency measures proposed might be followed to develop measures that can serve as a general model which may be applicable to different situations. Incorporating these parameters, a method may be developed to model a more realistic situation.

GTE does not involve ratio level data. There is need to incorporate effect of occupied elements and voids inside diagonal blocks; and effect of exceptional element (that require intercell travel) outside diagonals. We propose new measures incorporating these effects. Aim of grouping is to increase utilization of resources and to decrease loss due to intercell travel.

Ratio grouping efficiency $(R G E)$ is defined as ratio of Machine utilization net gain $(M U N G)$ to sum of machine utilization opportunity gain $(M U O G)$, Intercell travel loss (ICTL) (i.e. value of exceptional elements) and void value (i.e. value of voids, $V V$ ).

Ratio grouping efficiency, $R G E=[M U N G /(M U O G+I C T L+V V)]$

$$
V=\sum_{k=1}^{n o p f n o m c k(k)} \sum_{I=1}^{n p f k k k} \sum_{J=1}\left[N_{v}(I, J, K) \cdot P L M(I, J, K) \cdot P V(I, J, K) / W_{p} f k(k)\right]
$$

where:

nomck $(k)$ - number of machines in $K^{\text {th }}$ cell

$N_{v}(I, J, K)=0$, if $I^{\text {th }}$ machine, $J^{\text {th }}$ part in cell $K$ has occupied elements

$=1$, if $I^{\text {th }}$ machine, $J^{\text {th }}$ part in cell $K$ is a vacant element

$P L M(I, J, K)$ - operation time of $I^{\text {th }}$ machine for $J^{\text {th }}$ part in $K^{\text {th }}$ cell

$P V(I, J, K)$ - production volume of $I^{\text {th }}$ part in $k^{\text {th }}$ cell

$$
I C T L=\sum_{I_{1}=1}^{n_{e}}\left[t_{h}\left(I_{1}, J_{e}\right) \cdot P V\left(1, J_{e}\right)+t_{c c}\left(J_{e}\right)\right]
$$


$n_{e} \quad-$ number of exceptional elements

$P V(1, \mathrm{~J}) \quad$ - part production volume of $J_{e}^{\text {th }}$ exceptional part

$t_{h}\left(I_{1}, J\right) \quad$ - handling time for $J_{e}^{t h}$ exceptional part

$t_{c}\left(J_{e}\right) \quad-$ transportation time for $J_{e}^{\text {th }}$ exceptional part

Setup time $(I, J, K)$ - setup time for $I^{\text {th }}$ machine, $J^{\text {th }}$ part in $K^{\text {th }}$ cell

(one can also take load/unload \& other idle times in account)

Incorporating ordinal level and ratio level data, a general model of Performance measure is now proposed \& named as Weighted Sequence Ratio Efficiency (WSRE). WSRE may be defined as weighted average of grouping technology efficiency \& Ratio Grouping efficiency. It is represented as:

$$
\mathrm{WSRE}=\alpha \cdot(R G E)+(1-\alpha) \cdot G T E
$$

where $\alpha$ is a constant ranging from zero to one.

\section{APOSTVUIT -ALGORITHM}

Step-by-step procedure for solution is as follows:

Step 1 - Data representation and input:

Form Machine Sequence Part Matrix (MSPM), Machine Part Operation Time Matrix $(M P L M), P V$, Setime matrix etc.

Step 2 - Form Part Machine to Machine Sequence Matrix (PMMSM), Part Machine to Machine Sequence Time Matrix (PMMSTM) \& Part Machine to Machine Sequence Time Volume Matrix (PMMSTVM) for each part.

Step 3 - Form Machine Sequence Part Load Volume (MSPLV) Matrix.

Step 4 - Form Standardized Machine Sequence Part Load Volume (SMSPLV) matrix.

Step 5 - Form Part-Part Correlation Matrix (PPCM).

Step 6 - Find principle components (i.e. Eigen vectors and Eigen values).

Step 7 - Perform Orthographic View Part Grouping Analysis (OVPGA) to group parts.

Step 8 - Form Machine Group by Computing \& Allocating on basis of MUNG, MUOG, and ICTL for each machine for different part families using eq. (4), (5), (6), (7).

Step 9 - Compute performance parameter i.e. grouping efficiency, GTE, RGE \& WSRE.

\section{RESULT \& DISCUSSION}

We consider problem of size $5 \times 7$ (i.e. 5 machines \& 7 parts) to show the working of the algorithm. Input (or output) matrix (Table I) is fed into algorithm. Now, Part Machine to Machine Sequence Matrix (PMMSM), Part Machine to Machine Sequence Time Matrix (PMMSTM) \& Part Machine to Machine Sequence Time Volume Matrix (PMMSTVM) for each part are formed (Table II for part 'p1'). From here, Machine Sequence Part Load Volume (MSPLV) Matrix is formed (Table III). Now, MSPLV is standardized to form $S M S P L V$ matrix. From SMSPLV matrix, correlation matrix, cormat between parts is formed. Now, principle component analysis is performed on cormat matrix. Two Principle components are shown in Fig. 1. These principle components are plotted to visualize the Groups as shown in Fig. 1. We get two groups with parts p1, p3, p5 and parts p2, p4, p6, and p7.

Now, machines are allocated to the part families. We consider 0.1 minutes for loading/unloading and transportation time for AGV's from one cell to another cell. For machine $\mathrm{m}_{1}$, machine utilization net gain $M U N G$ is 71.67 minutes for part family 1 (i.e. p1, p3, p9) and for part family 2 (i.e. p2, p4, p6, p7) are 67.33 minutes. Therefore $\mathrm{m}_{1}$ machine is allocated to part family 1 . For machine $\mathrm{m}_{2}, M U N G$ for part family 1 is 42.36 minute and for 
part family 2 is 120.27 minutes. For machine $\mathrm{m}_{3}, M U N G$ is 0 and 142.10 minutes, respectively. For machine $\mathrm{m}_{4}, M U N G$ is 71.58 minutes and 5.2 minutes, respectively. For machine $\mathrm{m}_{5}, M U N G$ is 88.85 minutes and 111.10 minutes, respectively. Machines $\mathrm{m}_{1}$ and $\mathrm{m}_{4}$ are allocated to part family 1 and $\mathrm{m}_{2}, \mathrm{~m}_{3} \& \mathrm{~m}_{4}$ are allocated to part family 2 . A cell formed by machines and part families by parts are shown in Table I.

Number of exceptional elements \& intercell travels is 5. Grouping efficiency is $80 \%$. Group technology efficiency is $64.3 \%$. Ratio Grouping Efficiency is $80.17 \%$. Weighted sequence Ratio efficiency is $72.24 \%$.

Further, a problem of size $10 \times 12$ (i.e. 10 machines $\& 12$ parts) is shown. Input data are represented in Table IV. Part families are shown in Fig. 2. We get three part families. The cells formed by machines, and part families by parts are shown in Table IV. The cells formed are represented in Table V and compared with ACCORD [16] (Nair, J. G. and Narendran T. T., 1999) \& an analytical-iterative clustering algorithm A.I.A. [14] (George, A. P. et al., 2003). APOSTVUIT gives same GTE \& combined objective function value (i.e. min. Within-cell load variation \& min. Intercell travel). Algorithm is tested for other problems of various sizes as shown in Table VI.

It is observed that the proposed algorithm for formation of part families and machine groups with operation sequence, operation time, production volume ,intercell travel costs, gives satisfactory results which are of good quality or same as existing literatures in its class .

Table I: Input and Output $M S P M, O T, P V \&$ Setup time matrix of size $5 \times 7$.

\begin{tabular}{|c|c|c|c|c|c|c|c|c|}
\hline \multicolumn{2}{|c|}{ Parts $\rightarrow$} & \multirow[b]{2}{*}{ p1 } & \multirow{2}{*}{ p3 } & \multirow{2}{*}{ p5 } & \multirow{2}{*}{ p2 } & \multirow{2}{*}{ p4 } & \multirow[b]{2}{*}{ p6 } & \multirow{2}{*}{ p7 } \\
\hline $\mathbf{M c} \downarrow$ & OS/OT & & & & & & & \\
\hline \multirow[b]{2}{*}{$\mathbf{m}_{1}$} & OS & 1 & 2 & 1 & 0 & 0 & 0 & 0 \\
\hline & OT & 0.96 & 0.49 & 1.0 & 0 & 0 & 0 & 0 \\
\hline \multirow[b]{2}{*}{$\mathbf{m}_{4}$} & OS & 3 & 1 & 3 & 0 & 0 & 0 & 2 \\
\hline & OT & 0.95 & 0.88 & 1.2 & 0 & 0 & 0 & 0.11 \\
\hline \multirow[b]{2}{*}{$\mathbf{m}_{2}$} & OS & 2 & 0 & 2 & 1 & 1 & 0 & 3 \\
\hline & OT & 0.63 & 0 & 0.83 & 0.86 & 0.63 & 0 & 0.39 \\
\hline \multirow[b]{2}{*}{$\mathbf{m}_{3}$} & OS & 0 & 0 & 0 & 2 & 2 & 1 & 0 \\
\hline & OT & 0 & 0 & 0 & 0.54 & 0.52 & 0.76 & 0 \\
\hline \multirow[b]{2}{*}{$\mathbf{m}_{5}$} & OS & 0 & 3 & 0 & 3 & 3 & 2 & 1 \\
\hline & OT & 0 & 0.73 & 0 & 0.04 & 0.7 & 0.62 & 0.72 \\
\hline \multicolumn{2}{|l|}{ PV } & 12 & 75 & 120 & 60 & 40 & 90 & 150 \\
\hline \multicolumn{2}{|c|}{ Setup time } & 0.5 & 0.75 & 1.25 & 0.92 & 1.0 & 0.33 & 0.66 \\
\hline
\end{tabular}

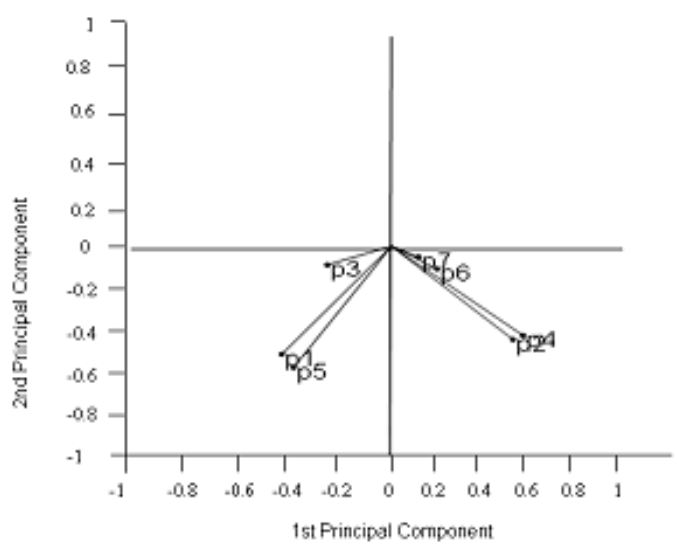

Figure 1: Orthographic View Part Grouping ; problem 1: part - machine $\left(\mathrm{p} 1 \times \mathrm{m}_{1}\right)$ size $7 \times 5$.
Table II: PMMSM, PMMSTM, PMMSTVM of size $5 \times 7$ for part $\mathrm{p} 1$.

\begin{tabular}{|c|c|c|c|c|c|c|}
\hline \multicolumn{2}{|c|}{ Machine $\rightarrow$} & \multirow[b]{2}{*}{$\mathbf{m}_{1}$} & \multirow[b]{2}{*}{$\mathbf{m}_{2}$} & \multirow[b]{2}{*}{$\mathbf{m}_{3}$} & \multirow[b]{2}{*}{$\mathbf{m}_{4}$} & \multirow[b]{2}{*}{$\mathbf{m}_{5}$} \\
\hline Mc. $\downarrow$ & OS/OT/PV & & & & & \\
\hline \multirow{3}{*}{$\mathbf{m}_{1}$} & OS & 1 & 1 & 0 & 1 & 0 \\
\hline & OT & 0.96 & 0.96 & 0 & 0.96 & 0 \\
\hline & $\mathbf{O T} \times \mathbf{P V}$ & 11.52 & 11.52 & 0 & 11.52 & 0 \\
\hline \multirow{3}{*}{$\mathbf{m}_{2}$} & OS & 0 & 1 & 0 & 1 & 0 \\
\hline & OT & 0 & 0.63 & 0 & 0.63 & 0 \\
\hline & $\mathbf{O T} \times \mathbf{P V}$ & 0 & 7.56 & 0 & 7.56 & 0 \\
\hline \multirow{3}{*}{$\mathbf{m}_{3}$} & OS & 0 & 0 & 0 & 0 & 0 \\
\hline & OT & 0 & 0 & 0 & 0 & 0 \\
\hline & $\mathbf{O T} \times \mathbf{P V}$ & 0 & 0 & 0 & 0 & 0 \\
\hline \multirow{3}{*}{$\mathbf{m}_{4}$} & OS & 0 & 0 & 0 & 1 & 0 \\
\hline & OT & 0 & 0 & 0 & 0.95 & 0 \\
\hline & $\mathbf{O T} \times \mathbf{P V}$ & 0 & 0 & 0 & 11.40 & 0 \\
\hline \multirow{3}{*}{$\mathbf{m}_{5}$} & OS & 0 & 0 & 0 & 0 & 0 \\
\hline & OT & 0 & 0 & 0 & 0 & 0 \\
\hline & $\mathbf{O T} \times \mathbf{P V}$ & 0 & 0 & 0 & 0 & 0 \\
\hline
\end{tabular}

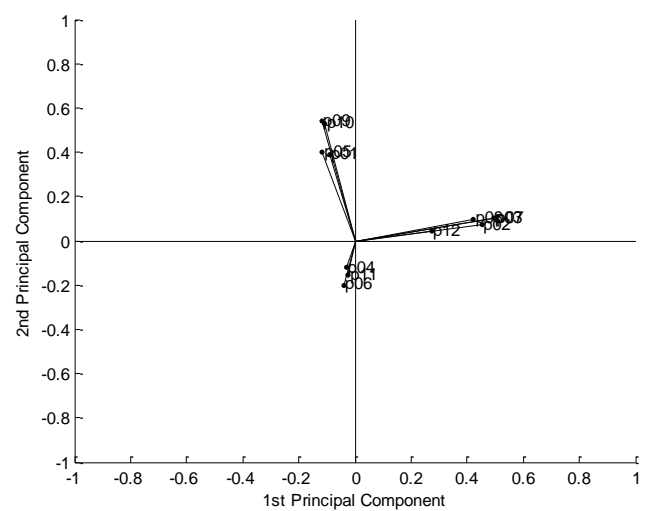

Figure 2: Orthographic View Part Grouping; problem 2: part - machine $\left(\mathrm{p} 1 \times \mathrm{m}_{1}\right)$ size $10 \times 12$. 
Kumar, Jain: Part-Machine Group Formation with Operation Sequence, Time and ...

Table III: Machine Sequence Part Load

Table VI: Algorithm performance on test Data set. Volume Matrix (MSPLV).

\section{$M S P L V=$}

\begin{tabular}{|c|c|c|c|c|c|c|}
\hline $\mathbf{p 1}$ & $\mathbf{p 2}$ & $\mathbf{p 3}$ & $\mathbf{p 4}$ & $\mathbf{p 5}$ & $\mathbf{p 6}$ & $\mathbf{p 7}$ \\
\hline 11.5 & 0 & 58.8 & 0 & 15.6 & 90.0 & 0 \\
\hline 11.5 & 0 & 0 & 0 & 15.6 & 0 & 0 \\
\hline 0 & 0 & 0 & 0 & 0 & 0 & 0 \\
\hline 11.5 & 0 & 0 & 0 & 15.6 & 0 & 0 \\
\hline 0 & 0 & 58.8 & 0 & 0 & 0 & 15.6 \\
\hline 0 & 0 & 0 & 0 & 0 & 0 & 0 \\
\hline 7.6 & 64.5 & 0 & 37.8 & 33.2 & 0 & 0 \\
\hline 0 & 64.5 & 0 & 37.8 & 0 & 0 & 0 \\
\hline 7.6 & 0 & 0 & 0 & 33.2 & 0 & 0 \\
\hline 0 & 64.5 & 0 & 37.8 & 0 & 0 & 0 \\
\hline 0 & 0 & 0 & 0 & 0 & 68.4 & 0 \\
\hline 0 & 0 & 0 & 0 & 0 & 0 & 0 \\
\hline 0 & 40.5 & 0 & 31.2 & 0 & 68.4 & 0 \\
\hline 0 & 0 & 0 & 0 & 0 & 0 & 4.4 \\
\hline 0 & 40.5 & 0 & 31.2 & 0 & 68.4 & 0 \\
\hline 0 & 0 & 105.6 & 0 & 0 & 0 & 0 \\
\hline 0 & 0 & 0 & 0 & 0 & 0 & 28.8 \\
\hline 0 & 0 & 0 & 0 & 0 & 0 & 0 \\
\hline 11.4 & 0 & 105.6 & 0 & 48.0 & 0 & 28.8 \\
\hline 0 & 0 & 105.6 & 0 & 0 & 0 & 28.8 \\
\hline 0 & 0 & 0 & 0 & 0 & 55.8 & 0 \\
\hline 0 & 0 & 0 & 0 & 0 & 0 & 0 \\
\hline 0 & 0 & 0 & 0 & 0 & 0 & 0 \\
\hline 0 & 0 & 0 & 0 & 0 & 0 & 0 \\
\hline 0 & 3.0 & 87.6 & 42.0 & 0 & 55.8 & 15.6 \\
\hline & & & & & & \\
& & & & \\
\hline
\end{tabular}

\begin{tabular}{|c|c|c|c|c|c|c|c|}
\hline \multirow[b]{2}{*}{$\underset{\dot{Z}}{\stackrel{0}{\dot{Z}}}$} & \multicolumn{2}{|c|}{$\begin{array}{c}\text { Problem } \\
\text { Size } \\
\end{array}$} & \multirow{2}{*}{ 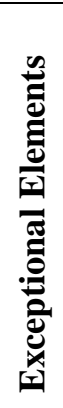 } & \multirow[b]{2}{*}{ 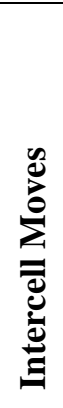 } & \multirow[b]{2}{*}{ 占 } & \multirow[b]{2}{*}{$\underset{0}{01}$} & \multirow[b]{2}{*}{ 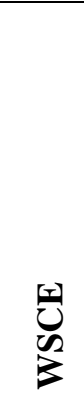 } \\
\hline & $\begin{array}{l}\tilde{\Xi} \\
\dot{\mathscr{E}} \\
\dot{\Xi} \\
\dot{0} \\
\dot{\mathbf{Z}}\end{array}$ &  & & & & & \\
\hline 1 & 4 & 5 & 0 & 0 & 100 & 85.48 & 92.74 \\
\hline 2 & 5 & 7 & 1 & 1 & 85.81 & 82.25 & 84.03 \\
\hline 3 & 5 & 8 & 6 & 5 & 64.30 & 80.17 & 72.24 \\
\hline 4 & 6 & 19 & 2 & 2 & 85.61 & 74.75 & 80.18 \\
\hline 5 & 12 & 20 & 8 & 8 & 83.93 & 73.29 & 78.61 \\
\hline 6 & 12 & 20 & 11 & 9 & 79.00 & 72.56 & 75.78 \\
\hline 7 & 20 & 20 & 3 & 3 & 94.5 & 87.86 & 91.18 \\
\hline 8 & 15 & 30 & 20 & 16 & 77.81 & 70.63 & 74.22 \\
\hline 9 & 20 & 37 & 24 & 24 & 72.50 & 70.10 & 71.30 \\
\hline 10 & 25 & 50 & 48 & 45 & 70.15 & 66.1 & 68.13 \\
\hline 11 & 20 & 55 & 14 & 18 & 82.30 & 73.90 & 78.10 \\
\hline 12 & 28 & 60 & 38 & 37 & 71.60 & 64.30 & 67.95 \\
\hline 13 & 30 & 65 & 57 & 50 & 77.88 & 68.48 & 73.18 \\
\hline 14 & 32 & 80 & 52 & 58 & 75.67 & 72.83 & 74.25 \\
\hline 15 & 35 & 90 & 53 & 55 & 78.89 & $\begin{array}{l}71.43 \\
\end{array}$ & 75.16 \\
\hline
\end{tabular}

Remark:

OS- Operation Sequence, $\quad$ OT- Operation Time, $\quad$ PV-Production Volume, $\quad$ MC. - Machine $(m)$, A.I.A.C.- An Analytical Iterative Cluster

Table IV: Output Machine Sequence Part Matrix (MSPM).

\begin{tabular}{|c|c|c|c|c|c|c|c|c|c|c|c|c|c|}
\hline \multicolumn{14}{|c|}{ VN } \\
\hline \multicolumn{2}{|c|}{ Parts $\rightarrow$} & \multirow[b]{2}{*}{ p1 } & \multirow[b]{2}{*}{ p5 } & \multirow[b]{2}{*}{ p9 } & \multirow[b]{2}{*}{ p10 } & \multirow[b]{2}{*}{ p2 } & \multirow[b]{2}{*}{ p3 } & \multirow[b]{2}{*}{ p7 } & \multirow[b]{2}{*}{ p8 } & \multirow[b]{2}{*}{ p12 } & \multirow[b]{2}{*}{ p4 } & \multirow[b]{2}{*}{ p6 } & \multirow[b]{2}{*}{ p11 } \\
\hline $\mathbf{M c} \downarrow$ & $\begin{array}{l}\text { OS/ } \\
\text { OT }\end{array}$ & & & & & & & & & & & & \\
\hline \multirow[b]{2}{*}{$\mathbf{m}_{1}$} & OS & 0 & 3 & 4 & 3 & 0 & 0 & 0 & 0 & 0 & 0 & 0 & 0 \\
\hline & OT & 0 & 0.63 & 0.54 & 0.39 & 0 & 0 & 0 & 0 & 0 & 0 & 0 & 0 \\
\hline \multirow[b]{2}{*}{$\mathbf{m}_{3}$} & OS & 1 & 5 & 1 & 1 & 0 & 0 & 0 & 0 & 0 & 0 & 0 & 0 \\
\hline & OT & 0.96 & 0.97 & $\begin{array}{ll}0 & .92 \\
\end{array}$ & 0.61 & 0 & 0 & 0 & 0 & 0 & 0 & 0 & 0 \\
\hline \multirow[b]{2}{*}{$\mathbf{m}_{4}$} & OS & 2 & 4 & 0 & 0 & 0 & 0 & 0 & 0 & 0 & 1 & 1 & 0 \\
\hline & OT & 0.95 & 0.89 & 0 & 0 & 0 & 0 & 0 & 0 & 0 & 0.07 & 0.11 & 0 \\
\hline \multirow[b]{2}{*}{$\mathbf{m}_{6}$} & OS & 3 & 1 & 2 & 2 & 0 & 0 & 0 & 0 & 0 & 0 & 0 & 0 \\
\hline & OT & 0.63 & 0.61 & 0.72 & 0.72 & 0 & 0 & 0 & 0 & 0 & 0 & 0 & 0 \\
\hline \multirow[b]{2}{*}{$\mathbf{m}_{8}$} & OS & 0 & 2 & 3 & 0 & 4 & 1 & 0 & 0 & 1 & 0 & 0 & 0 \\
\hline & OT & 0 & 0.94 & 0.92 & 0 & 0.04 & .08 & 0 & 0 & 0.02 & 0 & 0 & 0 \\
\hline \multirow[b]{2}{*}{$\mathbf{m}_{2}$} & OS & 0 & 0 & 0 & 0 & 1 & 2 & 1 & 1 & 3 & 0 & 0 & 0 \\
\hline & OT & 0 & 0 & 0 & 0 & 0.86 & 0.88 & 1.2 & 1.0 & 0.7 & 0 & 0 & 0 \\
\hline \multirow[b]{2}{*}{$\mathbf{m}_{5}$} & OS & 0 & 0 & 0 & 0 & 3 & 4 & 3 & 0 & 2 & 0 & 0 & 0 \\
\hline & OT & 0 & 0 & 0 & 0 & 0.54 & 0.49 & 0.81 & 0 & 0.72 & 0 & 0 & 0 \\
\hline \multirow[b]{2}{*}{$\mathbf{m}_{10}$} & OS & 0 & 0 & 0 & 0 & 2 & 3 & 2 & 2 & 0 & 0 & 0 & 0 \\
\hline & OT & 0 & 0 & 0 & 0 & 0.67 & 0.73 & 0.83 & 0.62 & 0 & 0 & 0 & 0 \\
\hline \multirow[b]{2}{*}{$\mathbf{m}_{7}$} & OS & 0 & 0 & 0 & 0 & 0 & 0 & 0 & 0 & 0 & 3 & 3 & 1 \\
\hline & OT & 0 & 0 & 0 & 0 & 0 & 0 & 0 & 0 & 0 & 0.83 & 0.99 & 0.77 \\
\hline \multirow[b]{2}{*}{$\mathbf{m}_{9}$} & OS & 0 & 0 & 0 & 0 & 0 & 0 & 0 & 0 & 0 & 2 & 2 & 0 \\
\hline & OT & 0 & 0 & 0 & 0 & 0 & 0 & 0 & 0 & 0 & \begin{tabular}{|l|}
0.72 \\
\end{tabular} & 0.76 & 0 \\
\hline \multicolumn{2}{|l|}{ PV } & 12 & 40 & 45 & 80 & 75 & 120 & 150 & 75 & 110 & 60 & 90 & 25 \\
\hline \multicolumn{2}{|c|}{ Setup time } & 0.5 & 1.0 & 1.4 & \begin{tabular}{l|l}
0.8 \\
\end{tabular} & 0.75 & 1.25 & 0.66 & 1.5 & 1.75 & 0.92 & .33 & 0.6 \\
\hline
\end{tabular}


Kumar, Jain: Part-Machine Group Formation with Operation Sequence, Time and ...

Table V: Comparison of the results of the proposed method over existing methods for the problem of size $12 \times 10$ (A.I.A.) \& $(10 \times 8)$ ACCORD.

\begin{tabular}{|c|l|c|c|c|c|}
\hline S. No. & \multicolumn{1}{|c|}{ Factors considered } & ACCORD & APOSTVUIT & A.I.A. & APOSTVUIT \\
\hline 1 & Problem Size $(\mathrm{m} \times \mathrm{p})$ & $10 \times 8$ & $10 \times 8$ & $12 \times 10$ & $12 \times 12$ \\
\hline 2 & Exceptional elements & 8 & 8 & 5 & 5 \\
\hline 3 & Grouping efficiency & 0.869 & 0.869 & 0.85 & 0.85 \\
\hline 4 & Group technology efficiency (\%) & 68.20 & 68.2 & 80.00 & 80 \\
\hline 5 & Ratio grouping efficiency (\%) & - & 80.58 & - & 81.16 \\
\hline 6 & Weighted sequence Ratio efficiencies & - & 72.24 & - & 80.58 \\
\hline 7 & Combined objective functions & 0.517 & 0.517 & 0.610 & 0.610 \\
\hline \multicolumn{7}{|l}{ ACCORD - Nair \& Narenderan, 1999 (COF); A.I.A. - George A. et. al., 2003 (COF) } \\
\hline
\end{tabular}

\section{CONCLUSION}

In this work, a novel algorithm, APOSTVUIT is developed to solve the cell formation problem. Algorithm has overcome the difficulty in dealing with non-binary, real valued data in solving CF problem. It includes operation sequence in input matrix. It also includes other important production data such as operation time, production volume $\&$ setup time. Further, intercell travel loss is considered in cell formation.

A new grouping performance measure is proposed for ratio level data. This involves effect of occupied elements, voids (i.e. diagonal elements) and exceptional elements (i.e. nondiagonal elements). A weighted performance measure is also proposed to take into ordinal and ratio level data. Algorithm gives flexibility to designer by removing constraint on number of cells and/or number of cell to be decided in advance.

The performance of proposed algorithm, APOSTVUIT is comparable \& good quality in its class in existing literature. Algorithm has immense industrial application potential. It is simple, easy to understand and implement, and supported by softwares. Designer needs knowledge of simple Matrix algebra only. There is no need of complex optimization techniques and programming skills. Proposed algorithm can be implemented by the use of free available software, Scilab- platform [23]. One can develop one's programme easily in this easy and very user friendly software. Moreover, there is much expensive commercial software such as SPSS, SAS, STAD, XLSTATS etc. which can be used to implement the algorithm.

\section{REFERENCES}

[1] Adenso-Diaz, B.; Lozano, S.; Eguira, I. (2005). Part-machine grouping using weighted similarity coefficients, Computers \& Industrial Engineering, Vol. 48, 553-570

[2] Albadawi, Z.; Bashir, H. A.; Chen, M. (2005). A mathematical approach for the formation of manufacturing cell, Computers \& Industrial Engineering, Vol. 48, 3-21

[3] Arvindh, B.; Irani, S. A. (1991). Principal components analysis for evaluating the feasibility of cellular manufacturing without initial-part matrix clustering, International Journal of Production Research, Vol. 32, 1909-1938

[4] Cheng, C. H.; Goh, C. H.; Lee, A. (2001). Designing group technology manufacturing systems using heuristic branching rules, Computers \& Industrial engineering, Vol. 40, 117-131

[5] Genwook, J.; Leep, H. R.; Parsaaei, H. R. (1998). A cellular manufacturing system based on new similarity coefficient which considers alternative routes during machine failure, Computers \& Industrial engineering, Vol. 34, 21-36 
[6] Harhalakis, G.; Nagi, R.; Proth, J. M. (1990). An efficient heuristic in manufacturing cell formation for group technology applications, International Journal of Production Research, Vol. 28, No. 1, 185-198

[7] King, J. R.; Nakornchai, V. (1982). Machine-component group formation in group technology: review and extension, International Journal of Production Research, Vol. 20, 117-133

[8] Kitaoka, M.; Nakamura, R.; Seriza, S.; Usuki, J. (1999). Multivariate analysis model for machine-part cell formation problem in group technology, International Journal of Production Economics, Vol. 60-61, 433-438

[9] Srinivasan, G.; Narendran, T. T. (1991). GRAFICS: a nonhierarchical clustering algorithm for group technology, International Journal of Production Research, Vol. 29, 463-478

[10] Stawowy, A. (2006). Evolutionary strategy for manufacturing cell design, The international Journal of Management Science: Omega, Vol. 34, 1 - 18

[11] Wang, J. (2003). Formation of machine cells and part families in cellular manufacturing systems using a linear assignment algorithm, Automatica, Vol. 39, 1607-1615

[12] Yasuda, K.; Yin, Y. (2001). A dissimilarity measure for solving the cell formation problem in cellular manufacturing, Computers \& Industrial Engineering, Vol. 39, 1-17

[13] Yin, Y.; Kazuhiko, K.; (2006). Similarity coefficient methods applied to the cell formation problem: A taxonomy and review, International Journal of Production Economics, Vol. 101, 329-352

[14] George, A. P.; Rajendran, C.; Ghosh, S. (2003). An analytical-iterative clustering algorithm for cell formation in cellular manufacturing systems with ordinal-level and ratio-level data, International Journal of Advanced Manufacturing Technology, Vol. 22, 125-133

[15] Nair, J. G.; Narendran, T. T. (1998). CASE: A clustering algorithm for cell formation with sequence data, International Journal on Production Research, Vol. 36, No. 1, 157-179

[16] Nair, J. G.; Narendran, T. T. (1999). ACCORD: A bicriterion algorithm for cell formation using ordinal and ratio-level data, International Journal of Production Research, Vol. 37, 539-556

[17] Selim, H. M.; Askin, R. G.; Vakharia, A. J. (1998). Cell formation in-group technology: review, evaluation and direction for future research, Computers and Industrial Engineering, Vol. 34, No. $1,3-20$

[18] Kusiak, A.; Wang, J. (1993). Efficient organizing of design activities, International Journal of Production Research, Vol. 31, No. 4, 753-769

[19] Gonzalez, R. C.; Wintz, P. (1987). Digital Image Processing, Addison-Wesley Publishing Company, New York

[20] Panneerselvam, R. (2004). Research Methodology, Prentice Hall of India Pvt. Ltd., New Delhi

[21] Gnanadesikan, R. (1997). Methods for Statistical Data Analysis of Multivariate observations, Wiley, New York, 7-15

[22] Rummel, R. J. (1988). Applied factor analysis, Northwestern University Press, Evanston

[23] Scilab: Platform - Scilab.org/ Platform 